\title{
Estimation of national and regional industry demand for photonics workers in the United States
}

Darrell Hull, Paul Illich, Christine Dossey

Darrell M. Hull, Paul I. Illich, Christine Dossey, "Estimation of national and regional industry demand for photonics workers in the United States," Proc. SPIE 9793, Education and Training in Optics and Photonics: ETOP 2015, 97932C (8 October 2015); doi: 10.1117/12.2223206

SPIE Event: Education and Training in Optics and Photonics: ETOP 2015, 2015, Bordeaux, France 


\title{
Estimation of National and Regional Industry Demand for Photonics Workers in the United States \\ Darrell M. Hull ${ }^{1}$, Paul I. Illich ${ }^{2}$, and Christine Dossey ${ }^{3}$ \\ ${ }^{1}$ University of North Texas; ${ }^{2}$ Southeast Community Collge; ${ }^{3} \mathrm{OP}-\mathrm{TEC}$ National Center for Optics and Photonics Technology Education
}

\begin{abstract}
All National or Regional Centers funded by the National Science Foundation for photonics education and training in the United States have undergone a rigorous attempt to estimate the demand for workers in the regions they serve. We present the procedure for establishing a sample frame, data collection mechanisms, and estimations from analyses that were used in the United States, as well as the results from these analyses. We also provide a template that may be used to replicate the procedures.
\end{abstract}

Keywords: Technicians, education, employment, economic demand

\section{INTRODUCTION}

The purpose of the present study was to assess U.S. industry demand for two-year degreed optics and photonics technicians. The study represents a follow-up study to a report completed in 2009, that assessed the national demand for optics and photonics technicians, including graduates of both 2-year and 4-year programs (Hull, Ruggiere, and Illich, 2009). Although the present study was conducted by the same authors and used many of the same questions included in the 2009 demand study, the inclusion criteria were altered to restrict inclusion to respondents who currently employ 2year degreed photonics technicians or plan to employ 2-year degreed photonics technicians. A copy of the survey instrument is included in the Appendix of this summary report. The survey targeted 4,217 firms listed in Laurin Publishing Company's Photonics Corporate Guide. The University of North Texas Survey Research Center, located in Denton, Texas, conducted the phone survey from January 2012 to March 2012. Among the 629 companies that were contacted, 346 met the screening criteria. Respondents were categorized into the following six firm size groups: 1-5, 610, 11-20, 21-50, greater than 50, and unknown. To adjust for differences in the percentage of companies within each firm size between the sample data and the population data, the responses were statistically weighted by firm size. Another difference between the 2009 study and the present study was the inclusion of a region variable to allow for regional level analyses. The present report provides a brief summary of the key findings. Figure 1 illustrates the seven regions identified by OP-TEC along with the total number of photonics employers within the region, as displayed in the white squares.

Education and Training in Optics and Photonics: ETOP 2015, edited by Eric Cormier, Laurent Sarger Proc. of SPIE Vol. 9793, 97932C · (C) 2015 SPIE, IEEE, OSA, ICO · doi: 10.1117/12.2223206 


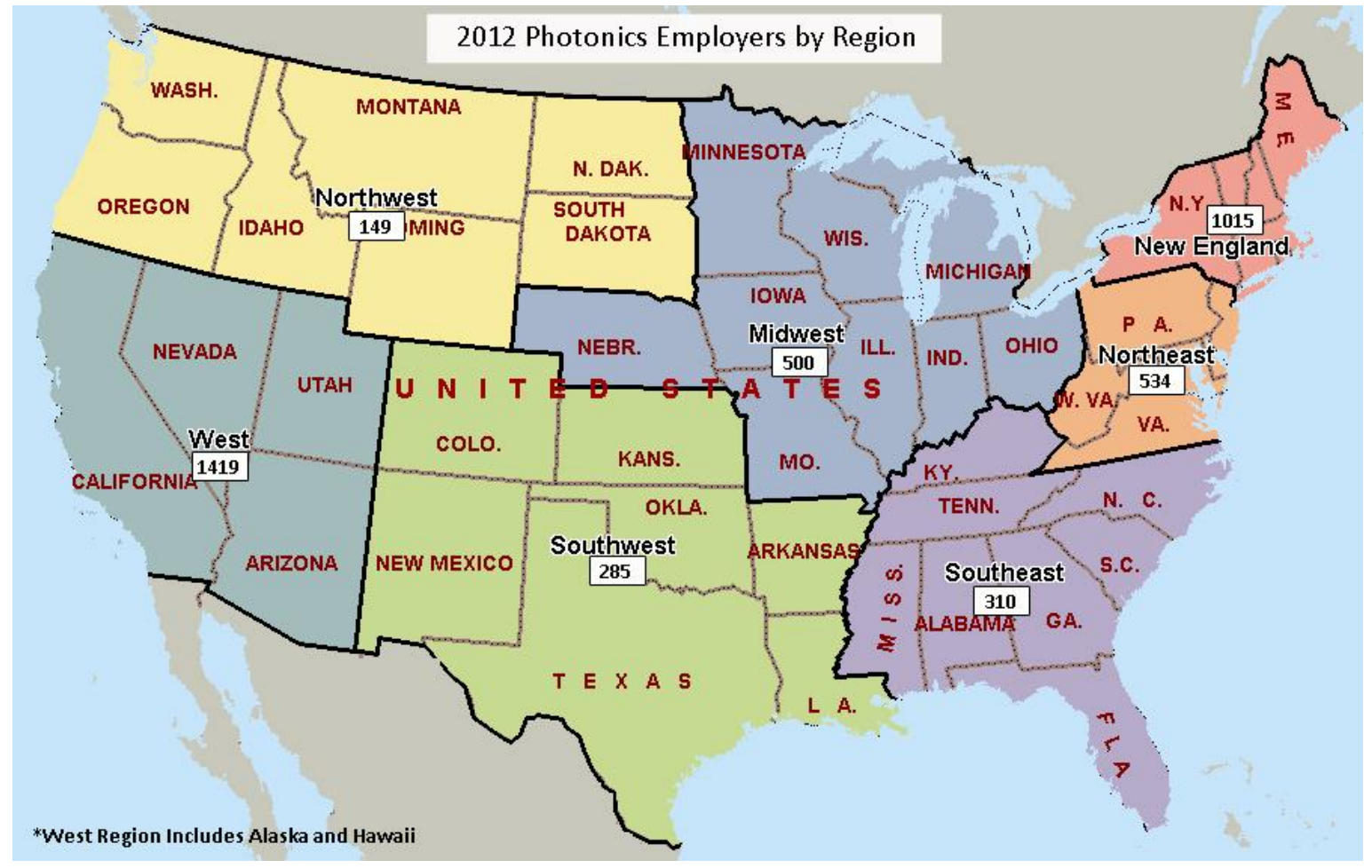

Figure 1. OP-TEC Optics and Photonics Employer Regions

The number and percent of sample respondents from each region compared to the number and percent of the national population of employers are shown in Table 1.

Table 1. Number of National and Sample Employers by Region

\begin{tabular}{|lcccc|}
\hline Region & \# of Employers & $\begin{array}{c}\text { \% of National } \\
\text { Total }\end{array}$ & $\begin{array}{c}\text { \# of Employers } \\
\text { in Sample }\end{array}$ & $\begin{array}{c}\text { \% of National } \\
\text { Sample }\end{array}$ \\
\hline Midwest & 500 & $11.9 \%$ & 50 & $15.0 \%$ \\
\hline New England & 1015 & $24.1 \%$ & 70 & $21.0 \%$ \\
\hline Northeast & 534 & $12.7 \%$ & 33 & $9.9 \%$ \\
\hline Northwest & 149 & $3.5 \%$ & 14 & $4.2 \%$ \\
\hline Southeast & 310 & $7.3 \%$ & 36 & $10.8 \%$ \\
\hline Southwest & 285 & $6.8 \%$ & 32 & $9.6 \%$ \\
\hline West & 1419 & $33.7 \%$ & 98 & $29.4 \%$ \\
\hline
\end{tabular}

The regional proportions of sample respondents were similar in pattern to the regional proportions of the target national population of employers. This finding suggests that the sample results can be applied to the target population, which we estimate to contain 4,217 firms in the optics and photonics industry. The estimates for the current number of photonics technicians as well as the 1-year and 5-year demand for photonics technicians were based on this assumption.

\section{Overall Results}

\section{Estimates/Projections of Current Number, 1-Year Demand, and 5-Year Demand}

Table 2 includes comparisons between the 2009 survey and the current survey for the estimated number of photonics technicians, 1-year demand for photonics technicians, and 5-year demand for photonics technicians. 
Table 2. Estimate of current number of photonics technicians and 1-year and 5-year demand projections.

\begin{tabular}{|cccc|}
\hline Year & $\begin{array}{c}\text { Current \# of } \\
\text { Technicians }\end{array}$ & $\begin{array}{c}\text { 1-Year } \\
\text { Demand }\end{array}$ & 5-Year Demand \\
\hline 2009 & 19,785 & 2,194 & 5,904 \\
\hline 2012 & 19,128 & 1,592 & 4,115 \\
\hline
\end{tabular}

Based on the results from the present study, an estimated 19,128 photonics technicians are currently employed in the U.S. This figure is very similar to the 2009 projection of 19,785. Because the instrument utilized in the present study included only companies that employed or planned to employ 2-year degreed photonics technicians, the projection included an adjustment based on the percentage of companies in the 2009 study that indicated they employed or plan to employ 2-year degreed photonics technicians. The conservative nature of the present estimate suggests that the actual number of photonics technicians in the U.S. is well above 20,000.

The 1-year demand and 5-year demand projections from the present study were not adjusted to reflect the more restrictive screening criteria of the 2012 survey. Because demand projections were based on a respondent's estimate of the number of photonics technicians they anticipate needing in the future, applying an adjustment could yield inflated projections. The present study projections are thus conservative projections of 1-year and 5-year demand for 2-year degreed photonics technicians.

The 1-year demand for the present study was 1,592 technicians and the 5-year demand was 4,115. These projections reflect the demand for only 2-year degreed technicians compared to the 2009 survey projections which reflected demand for both 2-year and 4-year degreed technicians. These results suggest that there continues to be an expansive gap between the estimated 280-300 two-year degreed photonics graduates produced each year and the existing demand for photonics technicians. In the 2009 survey, $74 \%$ of the respondents indicated a general need for additional photonics technicians. This figure increased $6 \%$ in the 2012 study with $80 \%$ of the respondents indicating a need for additional photonics technicians. Although the national unemployment rate has remained above $8 \%$ since 2009, the demand for photonics technicians has remained strong. This result represents one of the primary outcomes of the present study.

\section{Compensation of Photonics Technicians}

Figure 2 depicts the average annual salary from both the 2009 and 2012 demand surveys. The average annual salary for photonics technicians was $\$ 41,137$ with a standard deviation of $+/-\$ 13,896$ for the present study compared to $\$ 39,082$ and a standard deviation of $+/-\$ 13,320$ observed in the 2009 demand survey. This difference represents a 5.3\% increase in average annual compensation from 2009 to 2012. Given that the respondents in the present study were reporting compensation figures for 2-year degreed photonics technicians only, the actual percent increase is likely to be greater than the estimated $5.4 \%$ reported here.

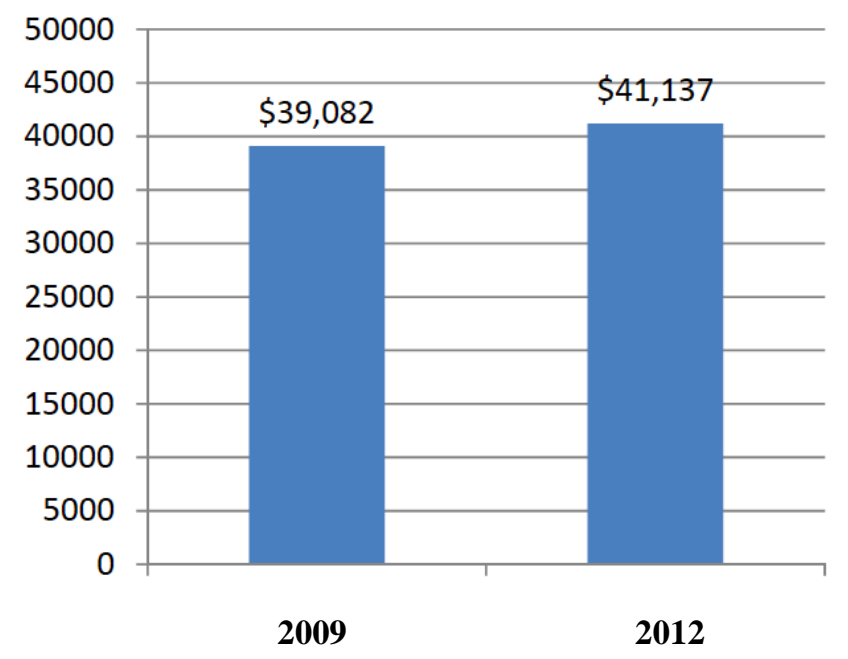

Figure 2. Average Annual Salary for Photonics Technicians 


\section{Satisfaction with Photonics Technicians}

Among the 346 survey respondents, 136 responded to the question related to satisfaction with entry-level preparedness of two-year degreed photonics technicians. Sixty-one percent $(61 \%)$ of respondents indicated that they were satisfied or very satisfied with the preparedness of 2-year photonics technician graduates. Thirty-three percent $(33 \%)$ of respondents indicated that they were neutral on the question and 6\% indicated they were either dissatisfied (5\%) or very dissatisfied $(1 \%)$. These findings suggest that while most employers are satisfied with the preparedness of 2-year degreed photonics technicians, there is substantial opportunity for improvement with nearly $40 \%$ of respondents expressing neutrality or dissatisfaction.

\section{Interest in Online Photonics Training}

Among the 346 survey respondents, 155 of the company representatives responded to the question assessing interest in online training for their photonics technicians. Forty-six percent (46\%) of the respondents indicated that they would be interested in online education/training for their photonics technicians to enhance the understanding of photonics concepts. Assuming that all of the $53.9 \%$ of the respondents who chose not to answer the training question would have no interest in online training, the $46 \%$ who did indicate an interest translates to 1,045 companies nationally that would have an interest in online training for their photonics technicians.

\section{Gender and Ethnicity}

Figure 3 depicts the percentage of photonics technicians by gender and ethnicity for the current demand study and the 2009 study.

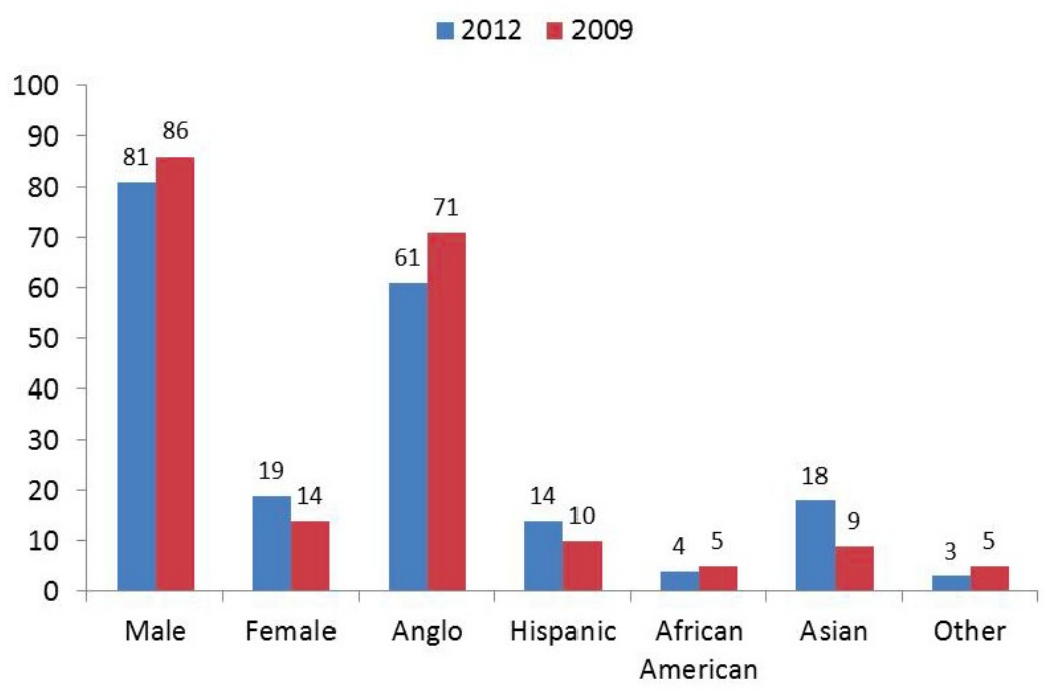

Figure 3. Percent of Photonics Technicians by Gender and Ethnicity

The percentage of female photonics technicians increased by 5 percentage points and the percentage of minority photonics technicians increased by 10 percentage points. However, these changes may be at least partly due to the differences in survey methodology with the 2012 survey focusing on companies who currently employ or plan to employ 2 -year degreed photonics technicians. Estimates from the current demand survey suggest that $19 \%$ of U.S. photonics technicians are female and $81 \%$ are male. In terms of ethnicity, it estimated that $61 \%$ of photonics technicians are Anglo, 14\% Hispanic, 4\% African American, and 18\% Asian. The percentage of Asian technicians is twice the percentage reported in 2009. Although these findings appear to suggest that substantial progress has been made in increasing gender and ethnic diversity among photonics technicians, the results should be interpreted with caution based on methodological differences between the two studies. 


\section{Educational Qualification Preferences for Photonics Technicians}

Figure 4 depicts percent of respondent preferences for the educational background necessary for a photonics technician to be successful.

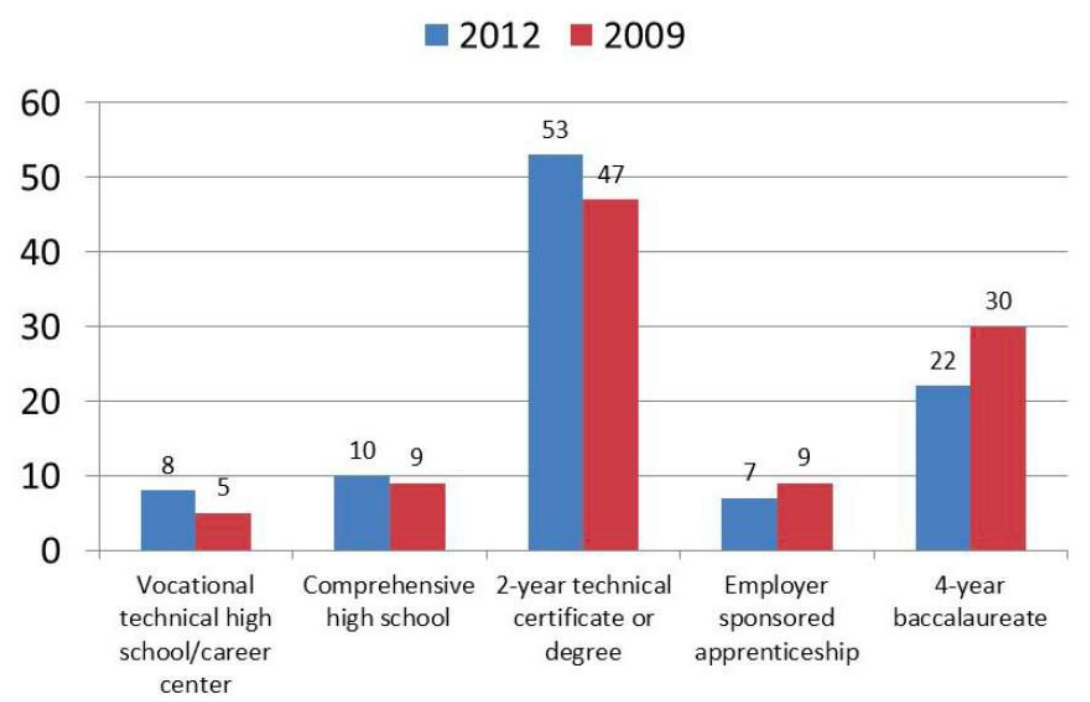

\section{Figure 4. Percent of Respondents by Educational Background}

In the current survey, $53 \%$ of respondents indicated that a 2 -year degree or certificate was necessary for a photonics technician to be successful. This result was 6 percentage points higher than the 2009 result. For the current survey, only $22 \%$ of respondents indicated that a 4-year degree or certificate was necessary for a photonics technician to be successful. Although the results should be interpreted with caution based on methodological differences between the two studies, the findings confirm that the 2-year certificate or degree continues to be the preferred educational background among employers of photonics technicians.

\section{Regional Results}

Estimates/Projections of Current Number, 1-Year Demand, and 5-Year Demand by Region Estimates of the current number of photonics technicians, 1-year demand projections, and 5-year demand projections for photonics technicians are shown in the Table 3. The regional estimates and projections utilized the overall national estimates and projections in Table 2 as the aggregate targets. The relative regional proportions of employed technicians and perceived 1-year and 5- year demand projections were used to establish regional estimates and projections.

Table 3. Estimates/Projections of Current Number, 1-Year, and 5-Year Demand for Photonics Technicians by Region

\begin{tabular}{|lccc|}
\hline Region & $\begin{array}{c}\text { Current \# of } \\
\text { Technicians }\end{array}$ & 1-Year Demand & 5-Year Demand \\
\hline Southeast & 1,946 & 192 & 427 \\
\hline West & 4,739 & 463 & 1,102 \\
\hline Midwest & 3,829 & 214 & 725 \\
\hline New England & 5,868 & 339 & 849 \\
\hline Northeast & 612 & 192 & 495 \\
\hline Northwest & 1,051 & 46 & 136 \\
\hline Southwest & 1,083 & 146 & 381 \\
\hline
\end{tabular}


The New England and West regions employ the largest number of photonics technicians with the New England region employing over 5,800 technicians and the West over 4,700 technicians. The Northeast region employs the smallest number of photonics technicians. The projected 1-Year demand ranged from 46 technicians within the Northwest region to over 400 in the West region. The projected 5-Year demand ranged from 136 technicians in the Northwest region to over 1,100 technicians in the West region. The West and New England regions each have demand for more technicians than are produced nationally each year by 2 -year U.S. colleges.

Figure 5 depicts the percentage of respondents indicating a need for additional photonics technicians by region.

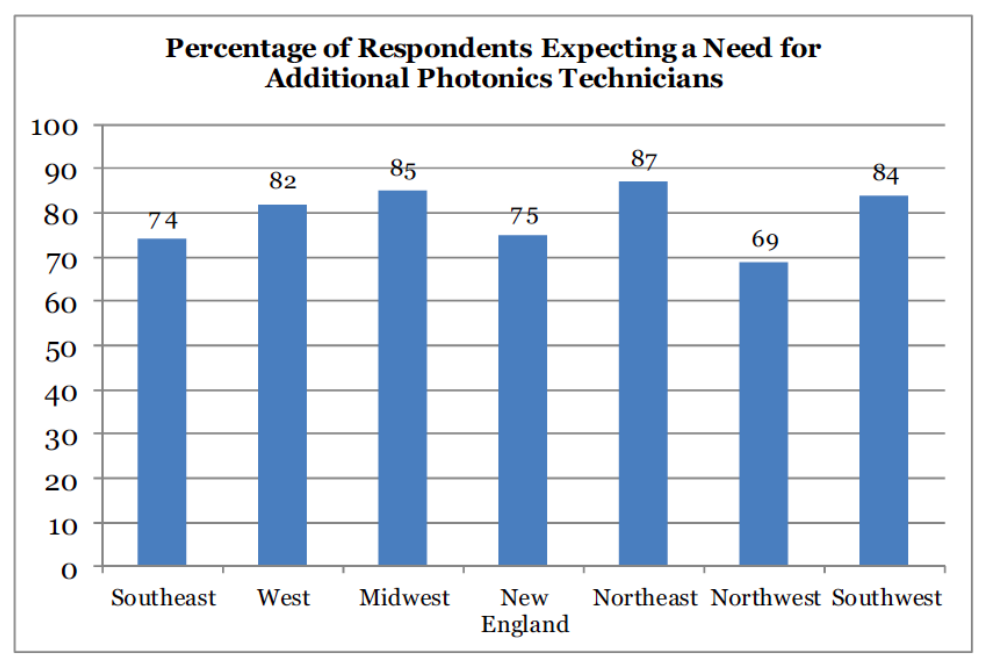

Figure 5. Need for Additional Photonics Technicians by Region

The percentage of respondents indicating a need for additional technicians ranged from $69 \%$ in the Northwest region to $87 \%$ in the Northeast region.

\section{Compensation of Photonics Technicians by Region}

Table 4 includes the average annual salary, sample size, and standard deviation for each of the seven regions.

Table 4. Average Annual Salary by Region

\begin{tabular}{|lccc|}
\hline Region & $\begin{array}{c}\text { Average Annual } \\
\text { Salary }\end{array}$ & Sample Size & Std. Deviation \\
\hline Midwest & $\$ 44,781$ & 27 & $\$ 20,862$ \\
\hline New England & $\$ 36,865$ & 33 & $\$ 7,948$ \\
\hline Northeast & $\$ 37,919$ & 11 & $\$ 7,692$ \\
\hline Northwest & $\$ 51,112$ & 5 & $\$ 12,181$ \\
\hline Southeast & $\$ 42,792$ & 20 & $\$ 17,779$ \\
\hline Southwest & $\$ 38,994$ & 16 & $\$ 9,576$ \\
\hline West & $\$ 41,782$ & 42 & $\$ 11,950$ \\
\hline
\end{tabular}

The average annual salary for entry-level photonics technicians ranged from a low of $\$ 36,865$ in the New England region to a high of $\$ 51,112$ in the Northwest region. The standard deviations were relatively large indicating substantial differences across employers.

\section{Satisfaction with Photonics Technicians by Region}

Table 5 includes the percentage and number of respondents indicating that they were very satisfied or satisfied with the preparedness of entry-level 2-year degree photonics technicians. 
Table 5. Satisfaction Ratings of Entry-Level Preparedness of Photonics Technicians

\begin{tabular}{|lcc|}
\hline Region & $\begin{array}{c}\text { Percentage of } \\
\text { Respondents Very } \\
\text { Satisfied or Satisfied }\end{array}$ & Sample Size \\
\hline Southeast & 59 & 17 \\
\hline West & 65 & 39 \\
\hline Midwest & 64 & 21 \\
\hline New England & 67 & 31 \\
\hline Northeast & 44 & 9 \\
\hline Northwest & 71 & 4 \\
\hline Southwest & 40 & 14 \\
\hline
\end{tabular}

The percentage of respondents satisfied with the preparedness of entry-level photonics technicians ranged from $40 \%$ in the Southwest region to $67 \%$ in the New England region.

Interest in Online Photonics Training by Training

Table 6 includes the percentage and number of respondents indicating an interest in online training for their photonics technicians.

Table 6. Percentage of Respondents Interested in Online Training Opportunities

\begin{tabular}{|lcc|} 
Region & $\begin{array}{c}\text { Percentage of } \\
\text { Respondents Interested } \\
\text { in Online Training }\end{array}$ & Sample Size \\
\hline Southeast & 44 & 18 \\
\hline West & 44 & 45 \\
\hline Midwest & 56 & 27 \\
\hline New England & 35 & 36 \\
\hline Northeast & 68 & 12 \\
\hline Northwest & 23 & 5 \\
\hline Southwest & 60 & 13 \\
\hline
\end{tabular}

The percentage of respondents interested in online training for their photonics technicians ranged from $23 \%$ in the Northwest region to $68 \%$ in the Northeast region.

\section{Key Findings}

The present study was designed to assess both national and regional demand for 2-year degreed photonics technicians. The study produced the following key findings:

1. The estimated number of 2-year degreed photonics technicians employed in the U.S. is 19,128 . 
2. An estimated 1,592 additional 2-year degreed photonics technicians are needed next year and 4,115 will be needed over the next five years.

3. After taking into account differences in survey methodology, the demand for photonics technicians appears to have increased since 2009.

4. There remains a tremendous gap between the demand for 2-year degreed photonics technicians and the U.S. capacity to produce 2-year graduates in optics and photonics.

5. The average annual salary for entry-level 2-year degreed photonics technicians is $\$ 41,137$, which represents over a $5 \%$ increase from the 2009 estimate.

6. While the majority $(61 \%)$ of employers expressed satisfaction with the preparedness of entry-level 2-year degreed photonics technicians, there appears to be considerable opportunity for improvement in preparing graduates of photonics technicians programs.

7. Over 1,000 U.S. employers are estimated to have an interest in seeking online training for their photonics technicians.

8. It is estimated that among photonics technicians $19 \%$ are female, $14 \%$ Hispanic, $4 \%$ African American, and $18 \%$ Asian. Although the current estimates represent substantial increases in diversity compared to the 2009 demand study, the present study focused on companies that currently employed or planned to employ photonics technicians while the 2009 study included companies that only employed 4-year degreed technicians.

9. It is estimated that $53 \%$ of employers believe that a 2 -year degree or certificate is necessary for a photonics technician to be successful. The percent of respondents preferring a technician with a 2-year degree increased by 6 percentage points while the percent of respondents preferring a bachelor degree decreased by $8 \%$. Although the results should be interpreted with caution based on methodological differences between the two studies, the findings confirm that the 2-year certificate or degree continues to be the preferred educational background among employers of photonics technicians.

10. The largest number of employed technicians are located in the West and New England regions with nearly $70 \%+$ employers within each of the seven U.S. regions expressing a need for additional photonics technicians. Both the West and New England regions have greater 1-year demand for photonics technicians than the total number of 2-year degreed graduates in photonics produced annually.

The present findings are consistent with previous estimates and demand projections reported in a

2009 national photonics employer demand survey. The current study clearly demonstrates a need to increase the U.S. capacity to produce qualified photonics technicians to reduce the gap between the production of photonics graduates and strong employer demand. The results also show that there is substantial room for improvement in the preparedness of entry-level 2-year degreed photonics technicians. The present findings can be used to implement targeted national and regional strategies to meet industry demand of effectively prepared photonics technicians 


\section{APPENDIX}

\section{INTERVIEW SCRIPT 2012 OP-TEC NEEDS ASSESSMENT}

\section{Q: INTRO}

Hello, my name is with the University of North Texas Survey Research Center. May I speak to the human resources manager or the person in charge of hiring photonics technicians?

TO RESPONDENT: Hello, my name is with the University of North Texas Survey Research Center. We are conducting a survey of employers to get an understanding of the optics, laser and photonics- related jobs in your organization and the key knowledge and skills related to those jobs. We are conducting the survey for OP- TEC, which is a non- profit National Center that is funded by the National Science Foundation to support the education (or preparation) of community college students for positions in optics, lasers and photonics technology.

We're conducting this survey on OP-TEC's behalf so that they will have better information from companies about their expectations for people they hire.

If you have any questions regarding this study you may speak to a project manager at 800-687- 7055 . Your responses will remain confidential; we will only publish aggregated information.

Q: Q1 Do you currently employ individuals with a 4-year degree in science or engineering where the degree included significant optics or photonics content?

>>INTERVIEWER: IF ASKED, >>THIS INCLUDES ALL LOCATIONS WITHIN THE CONTINENTAL U.S.

Q: Q1A Do you plan to employ individuals with a 4-year degree in science or engineering where the degree included significant optics or photonics content?

Q: Q2 Do you currently have 2- year degreed photonics technicians or photonics- related technicians in your company?

>>INTERVIEWER: IF ASKED, >>THIS INCLUDES ALL LOCATIONS WITHIN THE CONTINENTAL U.S.

Interviewer: For all the remaining questions in the survey make certain the respondent understands that, where specified, these questions pertain only to photonics or photonics -related technicians and do not pertain to engineers and scientists with 4-year degrees or higher.

Q: Q3 In the next five years, do you anticipate a need in your company for 2-year degreed photonics technicians and/orphotonics- related technicians?

>>INTERVIEWER: IF ASKED, >>THIS INCLUDES ALL LOCATIONS WITHIN THE CONTINENTAL U.S.

IF $(\mathrm{Q} 2=2)$ and IF $(\mathrm{Q} 3=2)$ SKP THANK3

Q: Q4 Please indicate the approximate number of photonics technicians and photonics- related technicians currently employed in your company throughout the United States.

(IF GIVEN A RANGE, PROBE TO GET ONE NUMBER) (INTERVIEWER: USE 99999 FOR NR/DK)

IF $(\mathrm{Q} 2>1)$ SKP Q5 
Q: Q4B How many photonics technicians and photonics- related technician positions are not filled at this time? (INTERVIEWER: USE 99999 FOR NR/DK)

Q: Q4C How many total people are employed in your company at your location only?

Number

(IF GIVEN A RANGE, PROBE TO GET ONE NUMBER)

(INTERVIEWER: USE 99999 FOR NR/DK)

Q: Q4D How many total people are employed in your company at all locations throughout the United

States? Number (IF GIVEN A RANGE, PROBE TO GET ONE NUMBER)

Q: Q5 Over the next five years do you expect your need for photonics technicians and photonics- related technicians to increase, decrease or stay the same as they are now?

1. Increase 2. Decrease 3. Stay the same as they are now 9. DK/NR

IF $($ ANS = 2) SKP Q5C IF (ANS > 2) SKP Q6

Q: Q5A How much of an increase do you anticipate for the next YEAR? (INTERVIEWER: RESP CAN GIVE A NUMBER OR A PERCENTAGE, SELECT WHICH THEY)

1. NUMBER OF PEOPLE 2. PERCENTAGE OF PEOPLE 9. DK/NR

Q: Q5B How much of an increase do you anticipate for the next FIVE years?

(INTERVIEWER: RESP CAN GIVE A NUMBER OR A PERCENTAGE, SELECT WHICH THEY PROVIDE THEN ENTER INFO ON NEXT SCREEN)

1. NUMBER OF PEOPLE 2. PERCENTAGE OF PEOPLE 9. DK/NR SKP Q5

Q: Q5C How much of a decrease do you anticipate for the next YEAR?

(INTERVIEWER: RESP CAN GIVE A NUMBER OR A PERCENTAGE, SELECT WHICH THEY PROVIDE THEN ENTER INFO ON NEXT SCREEN)

1. NUMBER OF PEOPLE 2. PERCENTAGE OF PEOPLE 9. DK/NR

Q: Q5D How much of a decrease do you anticipate for the next FIVE years?

(INTERVIEWER: RESP CAN GIVE A NUMBER OR A PERCENTAGE, SELECT WHICH THEY PROVIDE THEN ENTER INFO ON NEXT SCREEN)

1. NUMBER OF PEOPLE 2. PERCENTAGE OF PEOPLE 9. DK/NR 
Q: Q6 What is the average yearly starting salary for an entry- level photonics technician or photonics- related technician in your organization? (INTERVIEWER: TRY TO GET THE ANNUAL AMOUNT, USE OTHERS AS LAST RESORT)

1. HOURLY RATE 2. WEEKLY 3. MONTHLY 4. ANNUAL SALARY 9. DK/NR IF (Q2 > 1) SKP Q7

Q: Q7 Which of the following categories best describes your industry?

1. Lighting and illumination

2. Communications

3. Medicine

4. Manufacturing/Materials Processing (INTERVIEWER: IF CLARIFICATION NEEDED, INDICATE THAT THIS CATEGORY INCLUDES OPTICAL OR SENSOR MATERIALS PROCESSING, HIGH- POWERED LASER MACHINING SYSTEMS, ALIGNMENT/MEASUREMENT/METROLOGY APPLICATIONS OR EQUIPMENT)

5. Opto- Electronics/Nanotechnology (INTERVIEWER: IF CLARIFICATION NEEDED, INDICATE THAT THIS CATEGORY INCLUDES MINIATURIZATION/MICROSYSTEMS, OPTICAL MICROLITHOGRAPHY, OR SEMICONDUCTOR AND SENSOR MATERIAL FABRICATION)

6. Imaging and Remote Sensing (INTERVIEWER: IF CLARIFICATION NEEDED, INDICATE THAT THIS CATEGORY INCLUDES ENVIRONMENTAL CONTROL/MONITORING APPLICATIONS, ASSEMBLY AND CHARACTERIZATION OF CAMERAS AND READOUT ELECTRONICS, HOMELAND SECURITY, OTHER SIGNAL/IMAGING PROCESSING, AND NATIONAL DEFENSE/TRANSPORTATION APPLICATIONS.)

7. Laser Original Equipment Manufacturing (INTERVIEWER: IF CLARIFICATION NEEDED, INDICATE THAT THIS CATEGORY INCLUDES DESIGN OR MANUFACTURE LASERS OR SYSTEMS USING LASERS)

8. Optics Manufacturing

9. Other (Please describe)

99. NR/DK

Q: Q8 In your organization, what is the educational background perceived as necessary for a technician to work successfully in photonics?

(PROBE IF ANSWER DOES NOT FIT. PROBE FOR ONE RESPONSE)

1. Vocational technical high school or career center

2. Comprehensive high school

3. 2- year technical or community college (certificate or associate degree)

4. Formal employer- sponsored apprenticeship program

5. Four- year baccalaureate

9. NR/DK

IF (Q2 > 1) SKP Q14

Q: Q9A How many of your technicians who work in photonics have obtained the following levels of education?

Not finished high school

High school only 
Two- year technical college

Four- year baccalaureate

Formal apprentice training program

Q:Q10 Please rate your satisfaction with the entry-level preparedness of 2-year college photonics technician graduates. Very Satisfied; Satisfied; Neutral; Dissatisfied, Very Dissatisfied

Q: Q11A How many of your technicians who work in photonics are: Hispanic

Black/African American

Asian

Another minority racial group

Q: Q12 Approximately what percentage of your technicians who work in photonics are female?

Q: Q13 Would your organization be interested in online education/training that would provide your technicians an opportunity to enhance their understanding of photonics concepts?

Q: Q14 Do you have any comments regarding the Photonics industry or photonics education that you would like to share with us today?

1. YES, (SPECIFY)

2. NO

9. NR/DK Q: THANK

\section{Q: Q15}

Would you be willing to participate in another potential photonics related survey in the future? IF (ANS > 1) SKP THANK

\section{Q: Q15A}

What is the best number to reach you at?

\section{NUMBER WE DIALED}

\section{NEW NUMBER}

9. DK/NR

\section{Q: Q15B}

Please tell me your first and last name again. FIRST: $\quad$ LAST:

THANK YOU VERY MUCH FOR YOUR TIME AND COOPERATION. HAVE A GOOD DAY. 